ARTIGO

\title{
A UTILIZAÇÃO DE JOGOS NO ENSINO DE MATEMÁTICA: UMA EXPERIÊNCIA COM ALUNOS DO ENSINO MÉDIO ${ }^{1}$
}

\author{
Suélen Costa Braz \\ Thamara Kristina Miranda \\ Cirléia Pereira Barbosa
}

\begin{abstract}
RESUMO
O presente trabalho apresenta o relato de uma experiência sobre a utilização do Jogo dos Sólidos Geométricos como recurso metodológico para o ensino de Matemática na Educação Básica. A proposta teve como objetivo principal fixar conceitos relacionados à temática como reconhecer os sólidos geométricos e suas propriedades, e calcular o volume e a área total - de forma lúdica e atrativa. O jogo foi aplicado para uma turma do $3^{\circ}$ ano do Ensino Médio de uma escola da rede estadual da cidade de Formiga (MG). Os resultados mostraram que o uso de jogos e situações desafiadoras, como recursos didáticos, possibilitaram um trabalho lúdico da Matemática na sala de aula. Além de ter a finalidade de fazer com que os alunos aprendam a matéria, os jogos também podem ser encarados como situações oportunas para trabalhar outras questões com os discentes, como socialização, cooperação, respeito, dentre outras.
\end{abstract}

Palavras-chave: Relato de experiência. Jogos. Matemática.

\section{INTRODUÇÃO}

O uso de materiais didáticos manipuláveis no ensino de Matemática tem sido discutido entre pesquisadores da área, sendo esses recursos utilizados desde séculos passados. Segundo Nacarato (2005, p. 1), “o uso de materiais manipuláveis no ensino foi destacado pela primeira vez por Pestalozzi, no século XIX, ao defender que a Educação deveria começar pela percepção de objetos concretos, com a realização de ações concretas e experimentações". Ainda conforme essa autora, no Brasil, a utilização de recursos didáticos nas aulas de Matemática teria surgido no ano de 1920, em que o ensino era baseado em atividades lúdicas, jogos, materiais manipuláveis, dentre outros recursos.

\footnotetext{
${ }^{1}$ Como citar este artigo: BRAZ, Suélen Costa.; MIRANDA, Thamara Kristina; BARBOSA, Cirléia Pereira. A utilização de jogos no ensino de Matemática: uma experiência com alunos do Ensino Médio. ForScience: revista científica do IFMG, v. 6, n. 1, e00365, jan./jun. 2018.
}

${ }^{2}$ Autor para correspondência: Suélen Costa Braz, UNIFEI, e-mail: suelemcostabe@ @otmail.com. 
Em relação aos jogos, esses se fizeram presentes ao longo da história da humanidade. Segundo Strapason e Bisognin (2013, p. 586), o jogo “[...] fez parte de várias classes sociais, tendo influência positiva no desenvolvimento afetivo, físico, social e moral de quem o joga, sendo um importante fator de socialização entre os povos". Para essas autoras, o jogo também é gerador de cultura entre os povos, pois por meio dele, o homem aprendeu regras de conduta que contribuíram para o seu convívio em sociedade.

No ensino de Matemática, os jogos são importantes recursos didáticos e podem contribuir para o desenvolvimento de habilidades matemáticas, como o raciocínio lógico. Por exemplo, os jogos estratégicos trabalham o raciocínio dedutivo nos momentos em que o jogador, durante a escolha dos lances, depara-se com situações em que necessita elaborar e reelaborar suas hipóteses. As atividades com jogos também propiciam o desenvolvimento de outras habilidades essenciais à aprendizagem da Matemática, como observação, concentração e generalização. Além disso, por meio dos jogos, o professor pode trabalhar a relação dos alunos com a Matemática de como a minimizar bloqueios que alguns discentes têm em relação a essa disciplina (BORIN, 2007).

Ainda sobre os jogos, os Parâmetros Curriculares Nacionais (BRASIL, 1998, p. 47) consideram que:

Os jogos podem contribuir para um trabalho de formação de atitudes enfrentar desafios, lançar-se à busca de soluções, desenvolvimento da crítica, da intuição, da criação de estratégias e da possibilidade de alterá-las quando o resultado não é satisfatório - necessárias para aprendizagem da Matemática.

Assim, utilizar jogos no ensino de Matemática, além de ter a intenção de fazer com que os alunos aprendam o conteúdo, o professor também pode conceber o jogo como uma situação oportuna para trabalhar outras questões com os discentes, como: socialização, cooperação, respeito, dentre outras.

Este artigo tem como objetivo relatar uma experiência com o uso do Jogo dos Sólidos Geométricos $^{3}$ e apresentar e discutir os resultados obtidos a partir de sua aplicação em uma turma de terceiro ano do Ensino Médio de uma escola da rede estadual da cidade de Formiga (MG). A proposta foi desenvolvida durante a disciplina "Laboratório para o Ensino de

\footnotetext{
${ }^{3}$ Este jogo foi adaptado da oficina "Jogo dos Poliedros", disponível em:

$\langle$ http://porteiras.s.unipampa.edu.br/pibid/files/2012/01/Mat-PDP-Oficina_Jogo_dos_Poliedros.pdf $>$. Acesso em 21 mai. 2015. 
Matemática”, cursada na graduação em Matemática e orientada pela terceira autora deste trabalho.

Optou-se por trabalhar com um jogo sobre sólidos geométricos no Ensino Médio devido à dificuldade apresentada pelos alunos em relação ao conteúdo de geometria espacial. Fato observado pelas autoras durante a realização dos estágios supervisionados, realizados anteriormente.

\title{
2 O JOGO COMO RECURSO DIDÁTICO NAS AULAS DE MATEMÁTICA
}

Para utilizar jogos como recursos didáticos, Borin (2007) ressalta o papel da orientação do professor nas situações em que os jogos são realizados em sala de aula, e o quanto são importantes para o desenvolvimento das habilidades gerais dos discentes, como analisar, argumentar, estimular a concentração e ter um melhor desempenho na atividade.

Quanto à importância do uso de jogos nas aulas de Matemática, Borin (2007, p. 9) ainda destaca:

\begin{abstract}
Um motivo para a introdução de jogos nas aulas de Matemática é a possibilidade de diminuir os bloqueios apresentados por muitos de nossos alunos que temem a matemática e sentem-se incapacitados de aprendê-la. Dentro da situação de jogo, onde é impossível uma atitude passiva e a motivação é grande, notamos que, ao mesmo tempo em que estes alunos falam matemática, apresentam também um melhor desempenho e atitudes mais positivas frente a seus processos de aprendizagem.
\end{abstract}

Em especial, essa mesma autora coloca a importância do desenvolvimento de habilidades específicas da Matemática, como o raciocínio lógico e o raciocínio dedutivo, que instigam os alunos a pensar e a repensar em suas jogadas. Ainda enfatiza que para se atingir os objetivos com a utilização de jogos no ensino é imprescindível que estes não sejam vistos apenas como diversão, mas como aliados para o desenvolvimento de habilidades.

Além de ser um fator motivacional para os alunos, o uso de jogos na sala de aula favorece a socialização, a fixação de conceitos já aprendidos e o trabalho em equipe, e permite ao professor identificar e diagnosticar alguns erros de aprendizagem e dificuldades encontradas pelos alunos. Em contrapartida, quando mal utilizados, podem ser criadas situações de "jogo pelo jogo", ou seja, os alunos apenas jogam sem saber por que jogam. 
Outro aspecto que pode ser visto como uma desvantagem é o tempo gasto para o preparo e a realização da atividade (GRANDO, 2000).

Salientamos que o uso de jogos nas aulas de Matemática deve ser realizado com o propósito de enriquecer o conhecimento dos alunos de maneira lúdica e atrativa, e não somente propiciar uma aula diferente. É essencial que, durante o jogo, os alunos façam os devidos registros solicitados pelo professor, e que o docente circule pela sala observando os grupos e fazendo as intervenções necessárias. Nesse sentido, Macedo, Petty e Passos (1997 apud GRANDO, 2000, p. 44) afirmam que:

[...] criar formas de registro para posteriormente análise é um instrumento valioso, na medida em que lhe permite conhecer melhor seus alunos, identificando eventuais dificuldades e oferecer condições para a criança reavaliar ações passadas, podendo criar novas estratégias e até mesma modificar os resultados.

Assim, registrar as atividades propostas pode ser um meio eficaz para o professor diagnosticar as dificuldades encontradas, ou mesmo ver o que os alunos aprenderam com o jogo.

Apoiamo-nos na literatura consultada para a elaboração, desenvolvimento e análise da proposta realizada com os alunos do terceiro ano do Ensino Médio. Na próxima seção, passamos a apresentar o Jogo dos Sólidos Geométricos e o contexto em que foi aplicado.

\section{DESCRIÇÃO DO CASO}

A proposta foi desenvolvida no dia 10/07/2015 em uma turma do terceiro ano do Ensino Médio - matutino - de uma escola estadual de Formiga (MG). A escola fica localizada no centro da cidade, e recebe alunos de várias classes socioculturais e econômicas. Segundo a professora regente, a turma era a melhor dentre os terceiros anos.

Participaram da proposta 32 alunos. A professora regente da turma também estava presente na sala, apenas observando, ou seja, não houve participação nem intervenção de sua parte. O tempo de realização foi de uma hora e quarenta minutos. O principal objetivo da proposta foi de fixar conceitos relativos aos sólidos geométricos de maneira lúdica e atrativa. Os conteúdos abordados foram: nomenclatura dos sólidos geométricos, planificação dos sólidos, vértices, arestas, faces, área total e volume. 
Para o desenvolvimento da proposta, a turma foi organizada em grupos de quatro alunos, onde jogava dupla contra dupla. Foram oito grupos no total.

\subsection{O Jogo dos Sólidos Geométricos}

O Jogo dos Sólidos Geométricos tem como propósitos: reconhecer os sólidos geométricos; reconhecer a planificação dos sólidos geométricos; identificar num sólido geométrico seus elementos: face, arestas e vértices; identificar num sólido geométrico sua área total e volume; e estimular o desenvolvimento da percepção espacial.

O jogo é constituído por 36 cartas de $6 \mathrm{~cm}$ x $8 \mathrm{~cm}$, confeccionadas com papel cartão, contendo os sólidos e suas respectivas características.

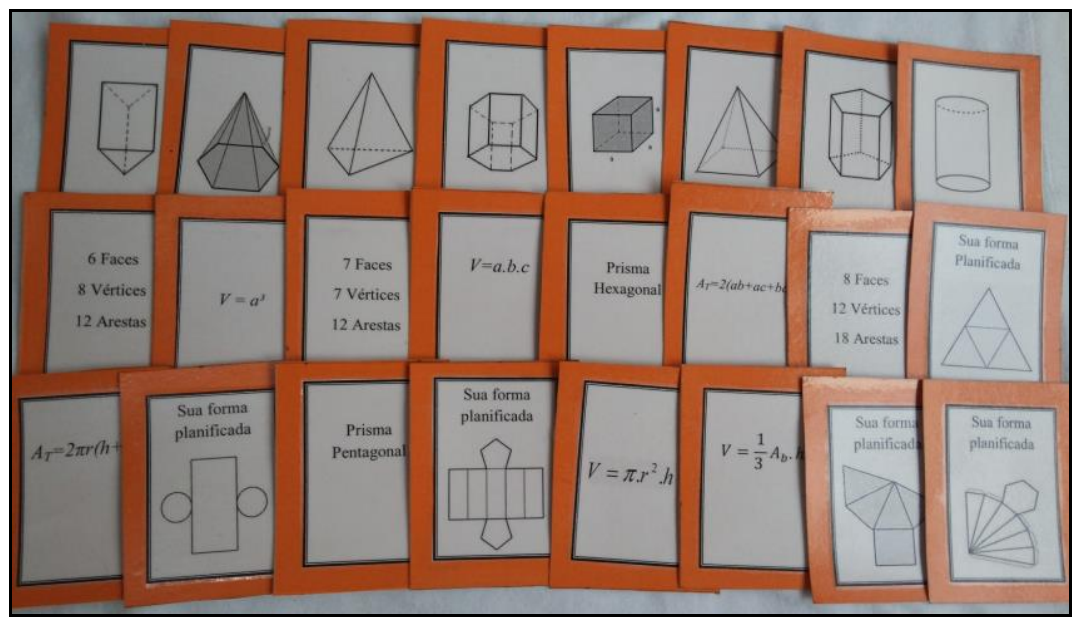

Figura 1- Cartas do Jogo dos Sólidos Geométricos Fonte: Fotografada pelas autoras.

O objetivo do jogo é formar "famílias" de quatro cartas. Cada "família" é constituída pela figura do sólido geométrico (obrigatoriamente) e por mais três características referentes ao sólido, podendo ser: o nome do sólido geométrico, a planificação do sólido geométrico, a área (total ou lateral), o volume ou número de elementos do sólido geométrico (vértices, arestas e faces). Ao todo, existem nove famílias e as duplas tentarão montar duas famílias com as cartas.

Inicialmente, escolhe-se a dupla de carteadores de forma aleatória. Após embaralhar as cartas, o baralho é oferecido à dupla adversária que procederá ao corte das cartas. Em seguida, serão distribuídas oito cartas para cada dupla de jogador, uma a uma com as faces viradas para baixo, o restante constituirá o "monte" de compras. 
Ao iniciar o jogo, a primeira dupla a jogar compra a carta de cima do monte de compras e tem duas opções: ficar com a carta, se ela servir no seu jogo, ou descartá-la. As cartas descartadas ficam com a face virada para cima sobre a mesa, formando o monte de descartes. A dupla adversária terá duas opções de compra: do monte de compras ou poderá pegar a última carta descartada sobre a mesa (apenas a última carta do monte de descartes poderá ser comprada). Vence o jogo a dupla que primeiro conseguir montar duas famílias com todas as suas cartas.

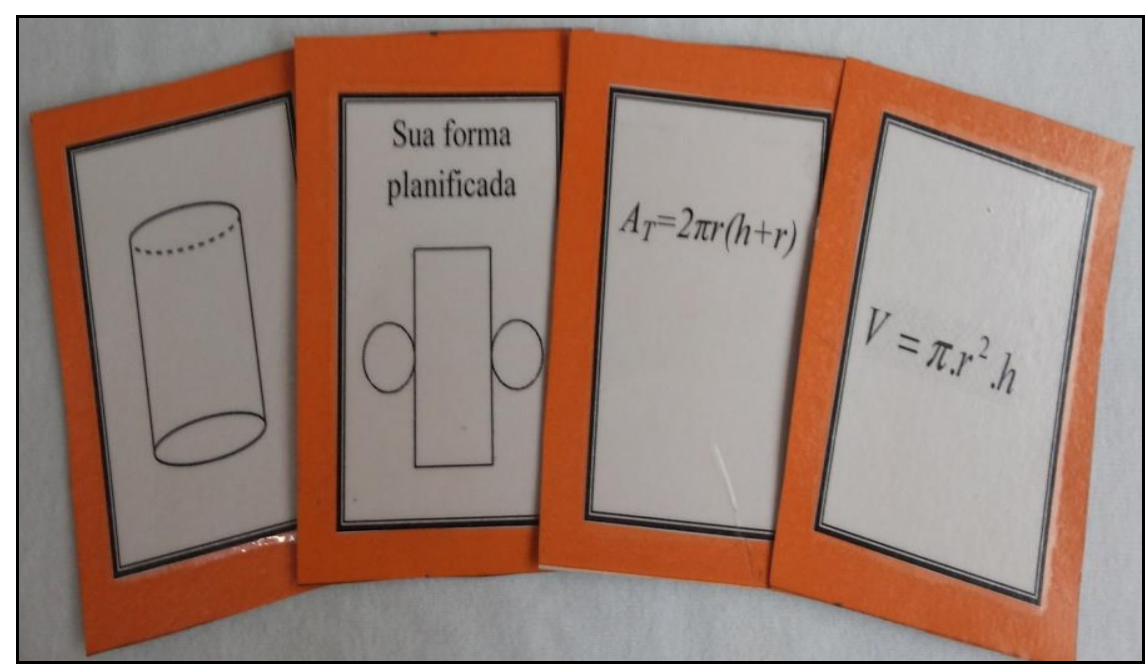

Figura 2 - Uma família do Jogo dos Sólidos Geométricos Fonte: Fotografada pelas autoras.

De acordo com Borin (2007, p. 15), o Jogo dos Sólidos Geométricos pode ser classificado como jogo de treinamento, pois "são idealizados para auxiliar a memorização ou fixação de conceitos, fórmulas e técnicas ligadas a alguns tópicos do conteúdo. Eles são utilizados quando, através de um diagnóstico, identificamos alguns alunos que necessitam de reforço em determinado tópico [...]”.

A seguir, descrevemos como a proposta foi desenvolvida na turma do $3^{\circ}$ ano do Ensino Médio.

\subsection{Desenvolvimento da proposta}

Inicialmente, foi feita a apresentação do material que compunha o jogo. Nessa etapa, o objetivo era que os alunos tentassem assimilar as famílias dos sólidos que teriam que formar, ou seja, uma carta contendo a figura de um sólido geométrico e outras três cartas com suas 
respectivas características. Aconselhadas por Rêgo R. M. e Rêgo R. G. (2009), deixamos os discentes explorarem livremente o material, dando-lhes o tempo necessário para que conhecessem o jogo.

Em seguida, foram apresentadas as regras do jogo para então dar início às atividades. Salientamos o fato de que, durante a realização da proposta, várias vezes os alunos solicitaram ajuda. Além disso, foi pedido aos discentes que registrassem as famílias encontradas durante a realização do jogo numa folha à parte (vide atividade 1 do Apêndice $\mathrm{A}$ ).

Durante a aplicação da proposta, mesmo diante de dificuldades como, por exemplo, fazer a transformação de unidades, calcular as potências e utilizar corretamente a fórmula de acordo com o problema proposto, observamos envolvimento das duplas com o jogo.

Em alguns casos, observamos que, à medida que as duplas compravam as cartas e notavam que não encontravam a carta que lhes daria a vitória, concluíam que a carta que precisavam estava com o adversário.

Em um grupo, registramos um empate, já que a carta que uma dupla precisava para ganhar estava com a dupla adversária. Assim, nenhuma das duplas quis ceder e descartar a carta que o adversário precisava para ganhar.

Em outra situação registramos a seguinte fala de um aluno durante o jogo: "Ah, joga essa carta aqui fora, porque isso vai dar trabalho pra gente!"'A carta a qual o aluno se referia era uma pirâmide de base hexagonal. A situação evidencia que o aluno encontrou um "obstáculo" ao se deparar com uma figura que não lhe era tão familiar.

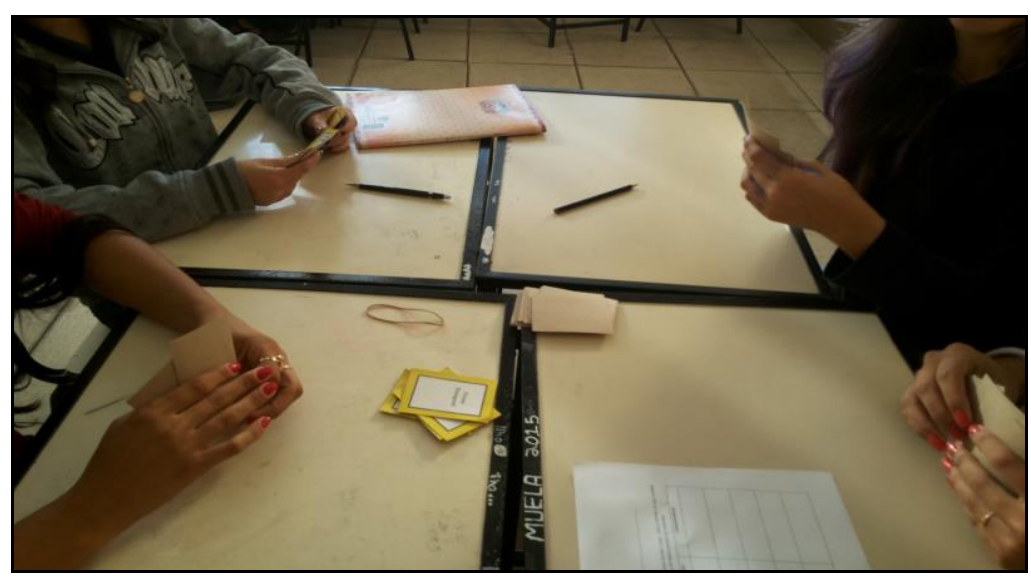

Figura 3- Aplicação do Jogo dos Sólidos Geométricos Fonte: Fotografada pelas autoras.

Em seguida, os alunos realizaram duas outras atividades sobre o conteúdo de sólidos geométricos (vide atividades 2 e 3 do Apêndice A). Uma dessas atividades consistia em julgar 
quatro afirmações e tinha o objetivo de fixar alguns conceitos trabalhados durante o jogo, como por exemplo: identificar o número de faces, vértices de arestas de um determinado prisma; calcular o volume do cilindro; calcular o volume e a área total de um paralelepípedo. A outra atividade referia-se a uma situação-problema envolvendo o cálculo da área total de um cubo.

Por fim, solicitamos aos alunos que respondessem a um questionário para avaliação da proposta (vide Apêndice B).

Nesta seção, foram apresentados o contexto e a proposta. Passaremos a discutir os principais resultados encontrados ao aplicar o Jogo dos Sólidos Geométricos na turma de terceiro ano do Ensino Médio.

\section{DISCUSSÃO DOS RESULTADOS}

Após a realização da proposta envolvendo a aplicação do Jogo dos Sólidos Geométricos, os dados coletados ${ }^{4}$ - por meio dos registros produzidos pelos alunos - foram analisados à luz da fundamentação teórica.

Foram construídos gráficos com o objetivo de analisar a quantidade de alunos que acertaram, erraram ou não fizeram as atividades propostas. Selecionamos algumas resoluções feitas pelos discentes e respostas apresentadas no questionário para avaliação da proposta. Para a escolha das respostas, utilizamos o critério de considerar as que possuíam justificativa coerente com a pergunta, além do propósito de relacioná-las com a fundamentação teórica.

Ressaltamos que a folha de registro e o questionário avaliativo foram numerados de 1 a 32 para manter o anonimato dos alunos. Por exemplo, o Aluno 29 na folha de registro é o mesmo Aluno 29 que respondeu ao questionário para a avaliação da proposta.

\subsection{Análise das resoluções apresentadas pelos alunos}

A seguir, analisamos algumas das resoluções de atividades que foram propostas após a aplicação do jogo.

\footnotetext{
${ }^{4}$ Para a coleta de dados, utilizamos o roteiro do Jogo dos Sólidos Geométricos (vide Apêndice A) em que os alunos fizeram o registro das atividades 1,2 e 3 , e um questionário (vide Apêndice B) para avaliar a intervenção realizada. Com a autorização da professora da turma, fizemos algumas fotografias para registrar o trabalho dos alunos em grupo. Foi tomado o cuidado para não fotografar o rosto dos discentes.
}

ForSci.: r. cient. IFMG, v. 6, n. 1, e00365, jan./jun. 2018. 


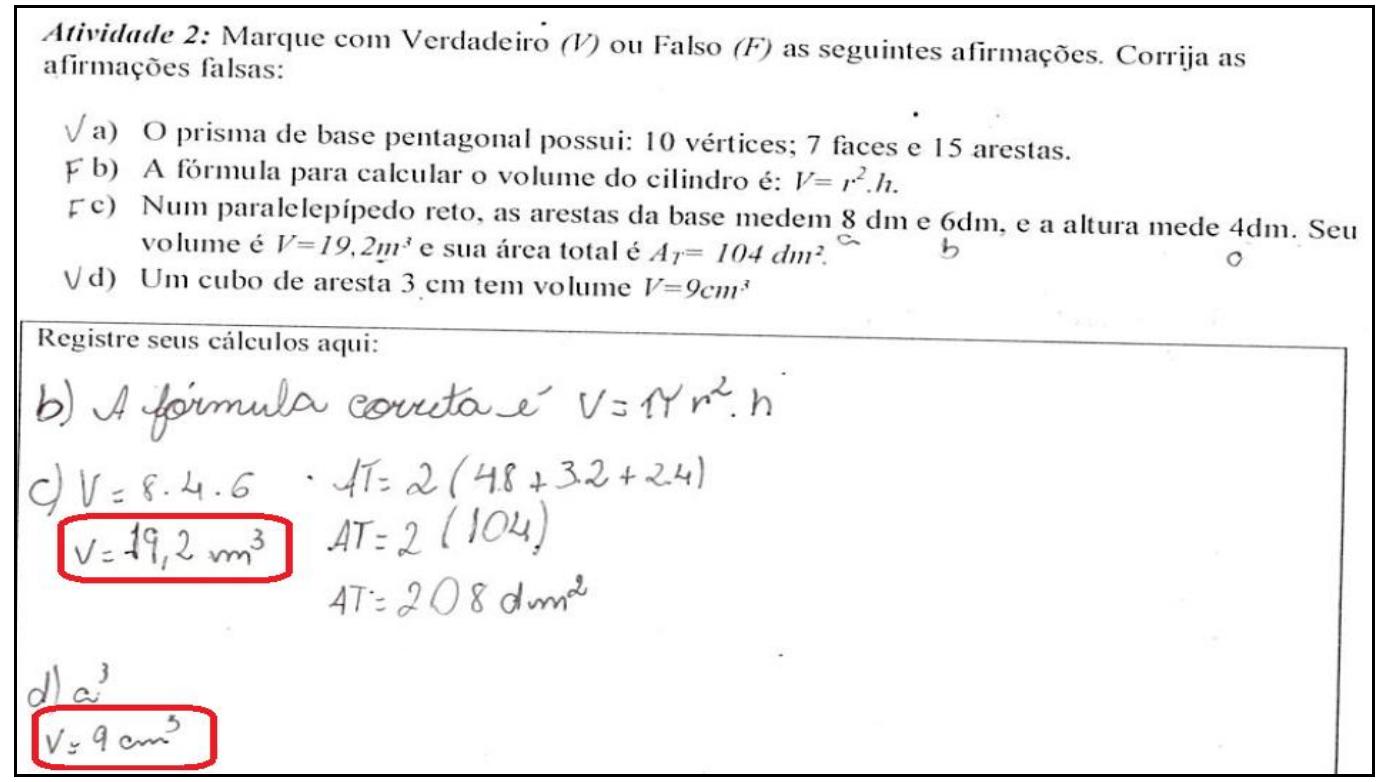

Figura 4- Resolução do Aluno 29

Fonte: Registro produzido pelo aluno.

Podemos observar na Figura 4, que o Aluno 29 utilizou corretamente as fórmulas, mas não soube fazer a transformação de unidades para encontrar o volume do paralelepípedo. No caso do volume do cubo, a resposta dada sugere o cálculo "três vezes três" em vez de "três elevado a três". Tais respostas evidenciam o fato de que a dificuldade encontrada por esse aluno possa estar em outros campos conceituais da Matemática, como por exemplo, na potenciação, e não exclusivamente no conteúdo de geometria.

$\mathrm{Na}$ atividade 3, o objetivo era analisar se os alunos sabiam diferenciar quando usar a fórmula do volume ou da área, numa situação-problema em que era necessário embrulhar uma caixa cúbica.

A figura seguinte mostra a resolução do Aluno 29. Pela resposta apresentada, nota-se que o aluno compreendeu como procederia a resolução do problema, utilizando inclusive a fórmula correta, mas observou-se uma "falha" na operação, o que pode ter acontecido por falta de atenção, já que a resposta dada ao exercício está correta. 


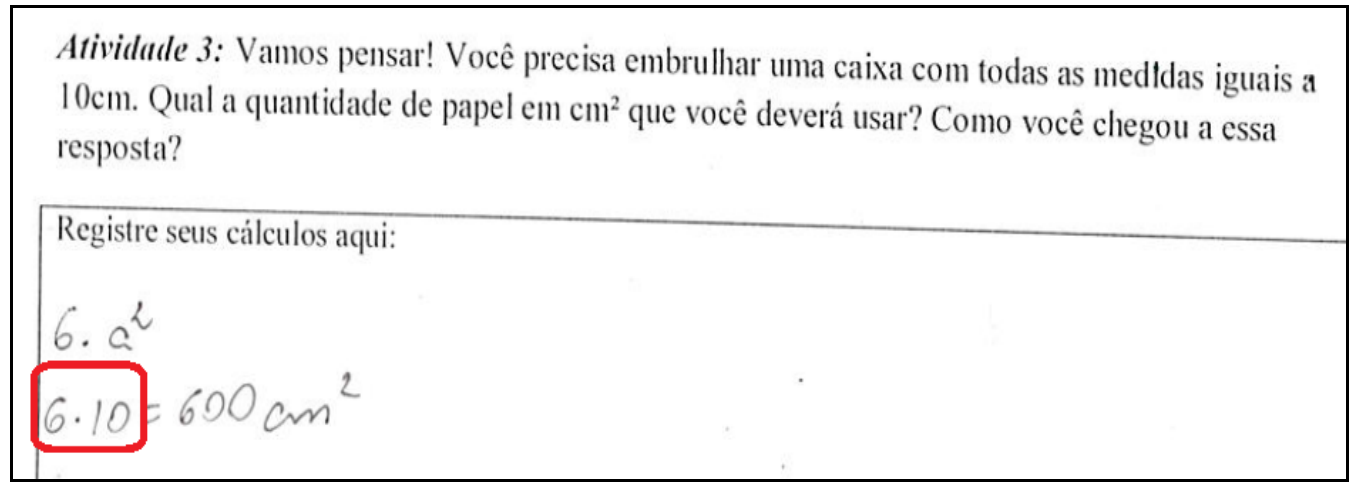

Figura 5- Resolução do Aluno 29

Fonte: Registro produzido pelo aluno.

Já na Figura 6, resolução do Aluno 19, os dados evidenciam nesse caso que o discente compreendia a fórmula do volume, porém não sabia a hora certa de utilizá-la, já que para a resolução da atividade 3, era necessário observar que seria correto utilizar os procedimentos para se calcular a área total da caixa.

Atividade 3: Vamos pensar! Você precisa embrullhar uma caixa com todas as medidas iguais a . $10 \mathrm{~cm}$. Qual a quantidade de papel ${\mathrm{em} \mathrm{cm}^{2}}^{2}$ que você deverá usar? Como você chegou a essa resposta?

Registre seus cálculos aqui: $\quad \begin{array}{ll}V & =a^{3} \\ V & =10^{3} \\ V & =1000 \mathrm{~cm}\end{array}$

Figura 6- Resolução do Aluno 19

Fonte: Registro produzido pelo aluno.

Nas Figuras 7 e 8 verificamos as resoluções do Aluno 30, salientando o fato de que as atividades 2 e 3 foram resolvidas corretamente. 


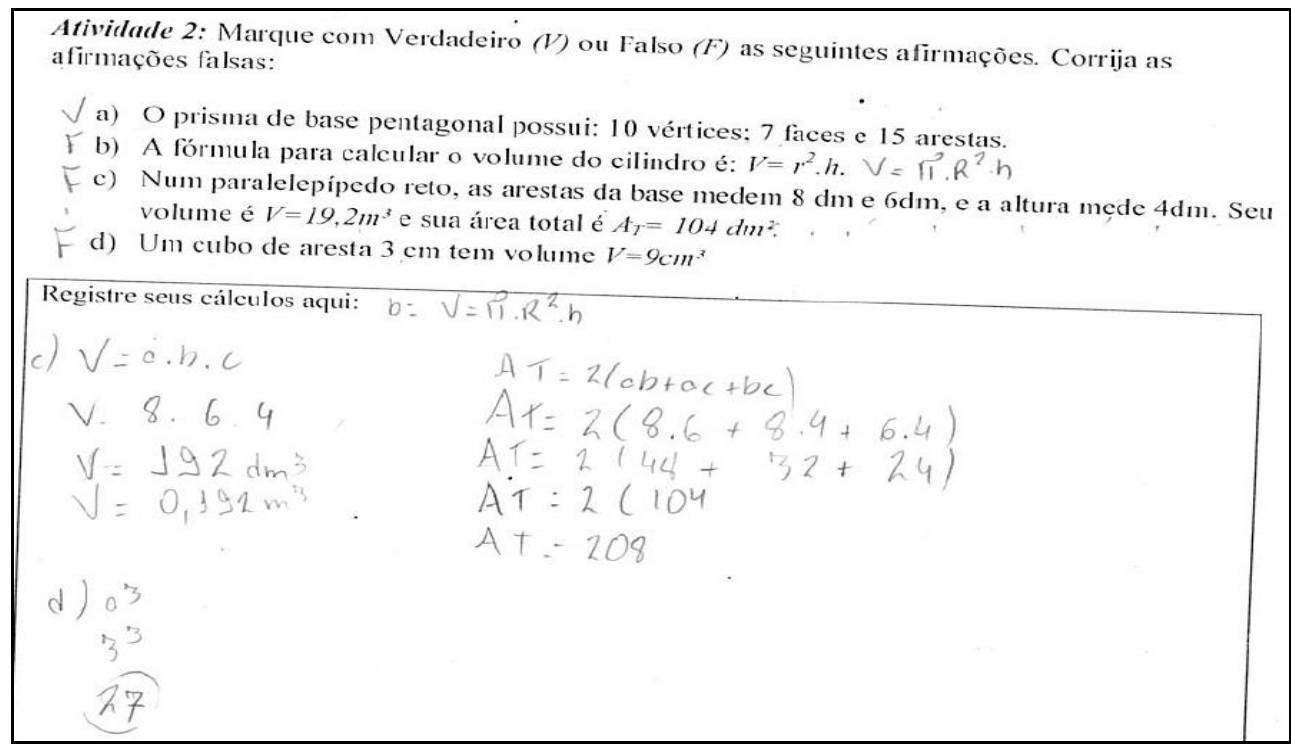

Figura 7 - Resolução do Aluno 30

Fonte: Registro produzido pelo aluno.

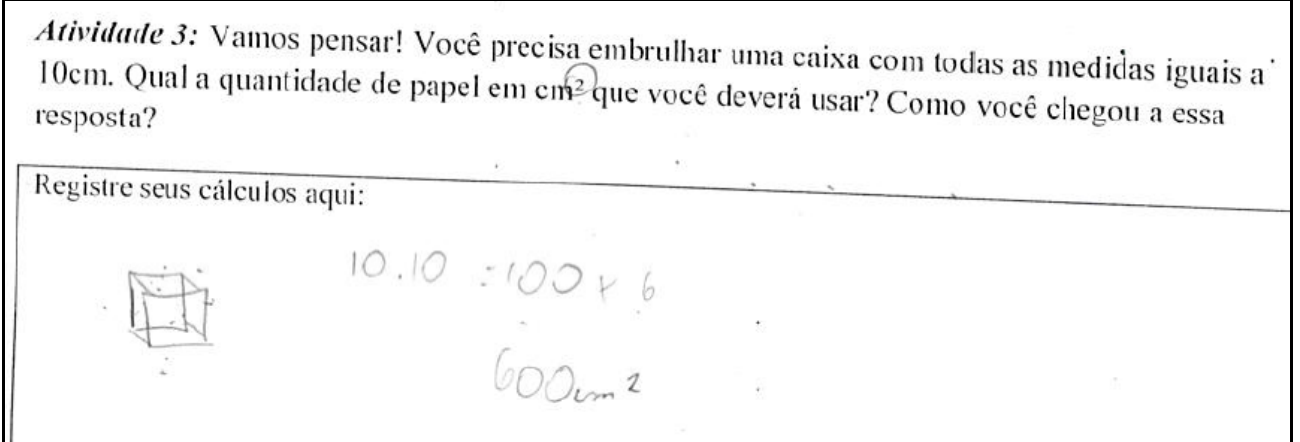

Figura 8 - Resolução do Aluno 30

Fonte: Registro produzido pelo aluno.

Com o objetivo de analisar a quantidade de alunos que resolveram as questões corretamente, que as resolveram de forma errada e os que não fizeram as atividades propostas, construímos alguns gráficos, com o auxílio do Software Excel, que são discutidos a seguir 5 .

- Atividade 2-B: A fórmula para calcular o volume do cilindro é: $V=r^{2} . h$.

$\mathrm{Na}$ referida atividade, como observado na figura seguinte, aproximadamente $66 \%$ dos alunos (21 alunos) acertaram, 28\% erraram (9 alunos) e 6\% (2 alunos) não fizeram a atividade proposta.

\footnotetext{
${ }^{5}$ Não apresentamos o gráfico para a atividade 2-A (vide apêndice A), pois todos os alunos a fizeram corretamente.
}

ForSci.: r. cient. IFMG, v. 6, n. 1, e00365, jan./jun. 2018. 


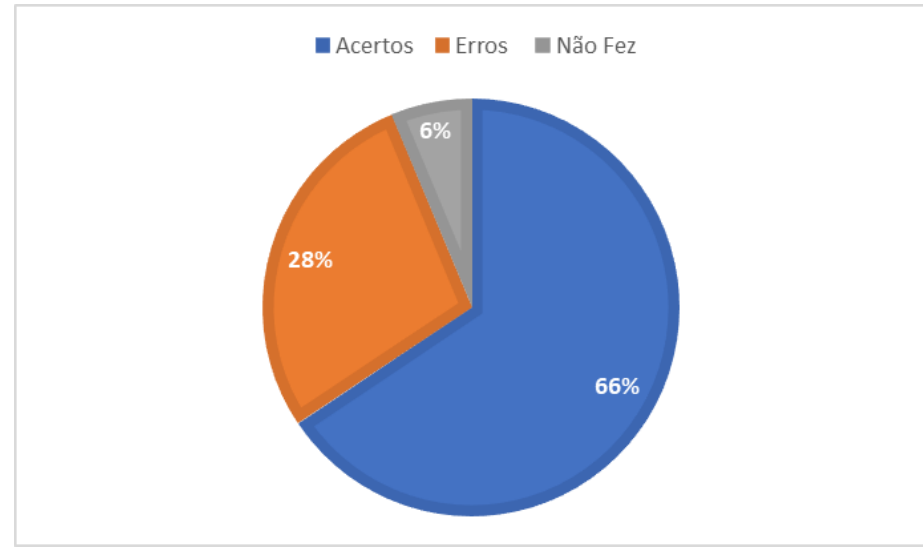

Gráfico 1 - Atividade 2-B

Fonte: Elaborado pelas autoras.

- Atividade 2-C: Num paralelepípedo reto, as arestas da base medem $8 \mathrm{dm}$ e $6 \mathrm{dm}$, e altura mede $4 \mathrm{dm}$. Seu volume é $V=19,2 \mathrm{~m}^{3}$ e sua área total é $A_{T}=104 \mathrm{dm}^{2}$.

$\mathrm{Na}$ terceira questão da atividade 2, os dados obtidos foram analisados para o volume e a área total, já que a questão envolvia ambos os conteúdos.

Podemos observar que, para o volume, 12,5\% dos alunos (4 alunos) acertaram, 84,4\% erraram (27 alunos) e 3,1\% (1 aluno) não fez. Já para a área total, 43,8\% dos alunos (14 alunos) acertaram, 53,1\% erraram (17 alunos) e 3,1\% (1 aluno) não fez. Os dados estão representados no gráfico seguinte.

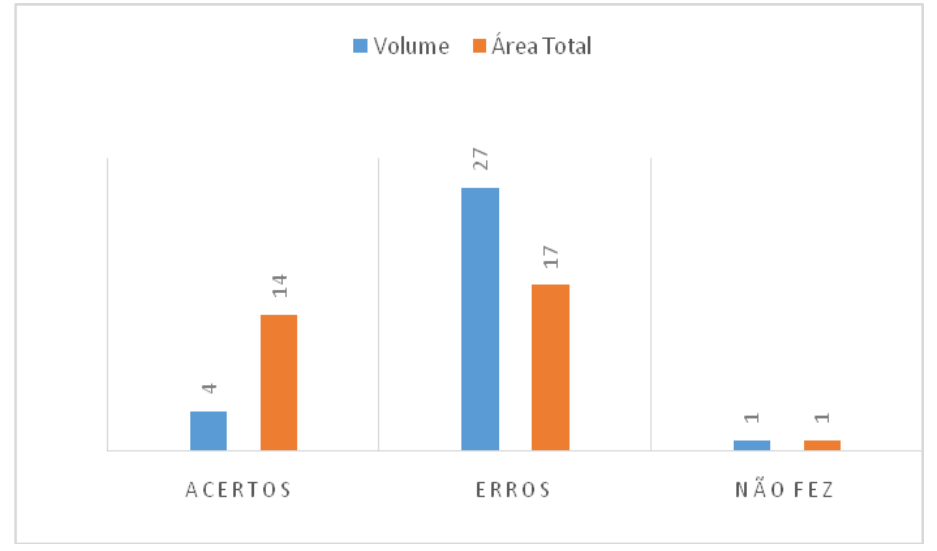

Gráfico 2 - Atividade 2-C

Fonte: Elaborado pelas autoras.

A análise do percentual de erros nesta atividade, destacando as resoluções do conteúdo de volume, sugere que a dificuldade apresentada pela maioria dos alunos (como no caso do aluno 29), advém do processo de transformação de unidades.

- Atividade 2-D: Um cubo de aresta $3 \mathrm{~cm}$ tem volume $V=9 \mathrm{~cm}^{3}$. 
Já na quarta questão, aproximadamente 68,8\% dos alunos (22 alunos) acertaram, $28,1 \%$ erraram (9 alunos) e 3,1\% (1 aluno) não fez.

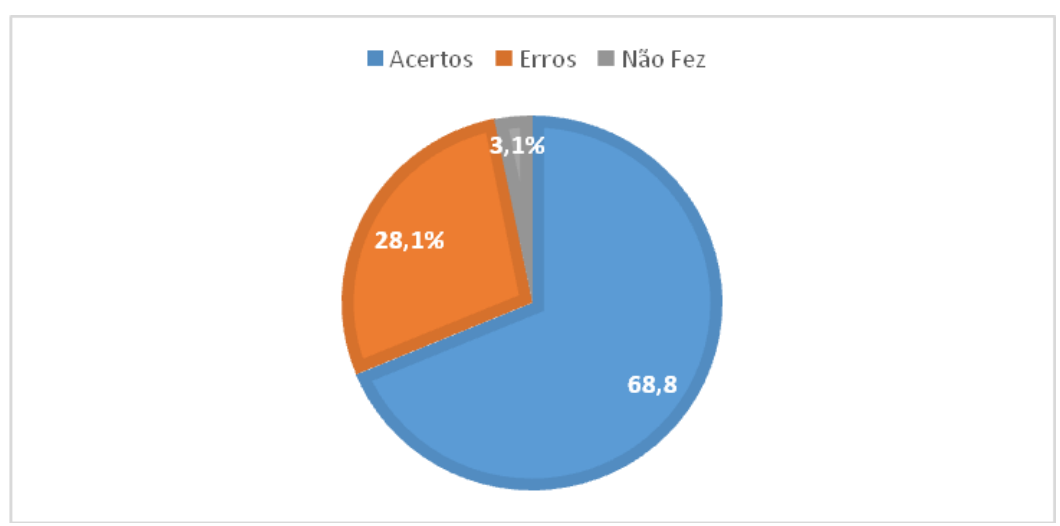

Gráfico 3 - Atividade 2-D

Fonte: Elaborado pelas autoras.

- Atividade 3: Vamos pensar! Você precisa embrulhar uma caixa com todas as medidas iguais a $10 \mathrm{~cm}$. Qual a quantidade de papel $\mathrm{em}^{\mathrm{cm}}{ }^{2}$ que você deverá usar? Como você chegou a essa resposta?

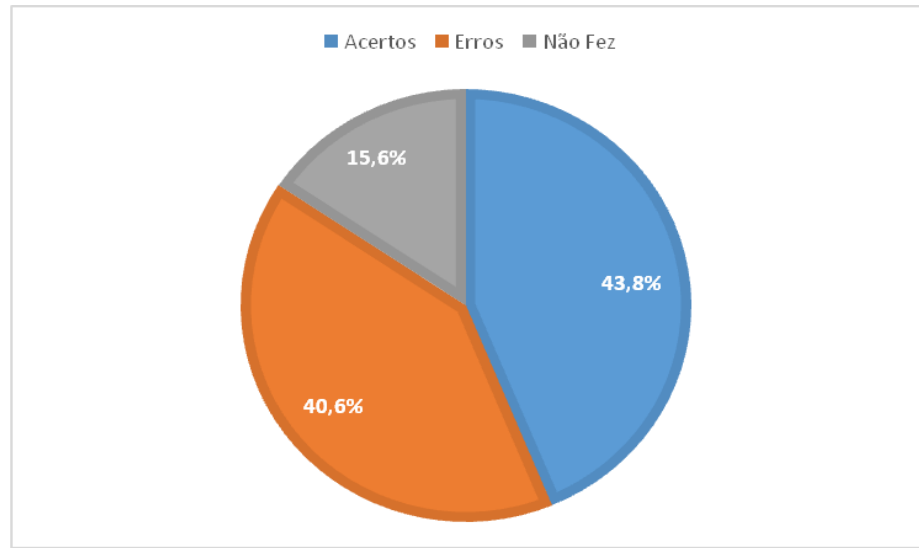

Gráfico 4 - Atividade 3

Fonte: Elaborado pelas autoras.

$\mathrm{Na}$ atividade 3, aproximadamente 43,8\% dos alunos (14 alunos) acertaram, 40,6\% erraram (13 alunos) e 15,6\% (5 alunos) não fizeram. Durante a correção da atividade, foi possível perceber que a maior quantidade de erros ocorreu devido ao fato de os alunos não conseguirem interpretar corretamente o problema proposto.

De modo gral, os dados evidenciaram que a resolução que obteve um maior percentual de acertos foi a Atividade 2-A, sendo que para a resolução desta atividade não era necessário 
nenhum cálculo. Já a Atividade 2-C, que envolvia o cálculo do volume, além de necessitar da transformação de unidade para a resolução correta da mesma, foi a que obteve o maior percentual de erro. Assim, percebemos que a maioria dos erros ocorreu em questões nas quais se exigia maior grau de dificuldade.

\subsection{Análise da intervenção realizada}

De acordo com Borin (2007), o jogo também desenvolve o aspecto motivacional, pois além de possibilitar o ensino da Matemática de uma forma lúdica e atrativa, permite uma mudança de atitude por parte dos alunos, fazendo com que demonstrem interesse por essa disciplina e tenham gosto em aprendê-la. A resposta apresentada pelo Aluno 26 à primeira pergunta do questionário evidencia que tal objetivo foi alcançado.

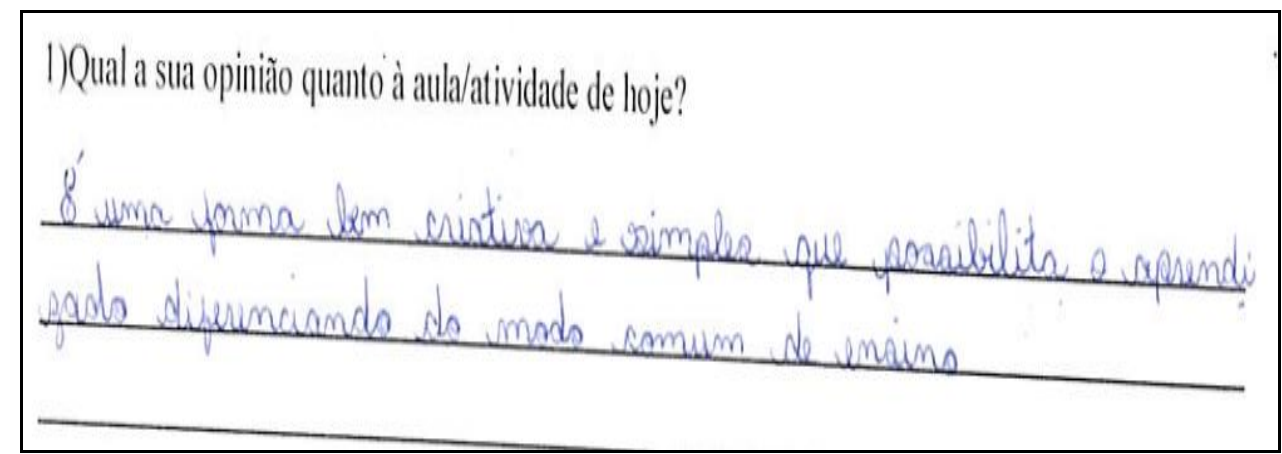

Figura 9 - Resposta do Aluno 26

Fonte: Imagem digitalizada pelas autoras.

Durante a aplicação do jogo, percebemos certa dificuldade dos alunos em relação aos conteúdos abordados no jogo. Isso pode ser evidenciado na fala de um aluno ao responder a segunda pergunta do questionário, como mostra a figura seguinte.

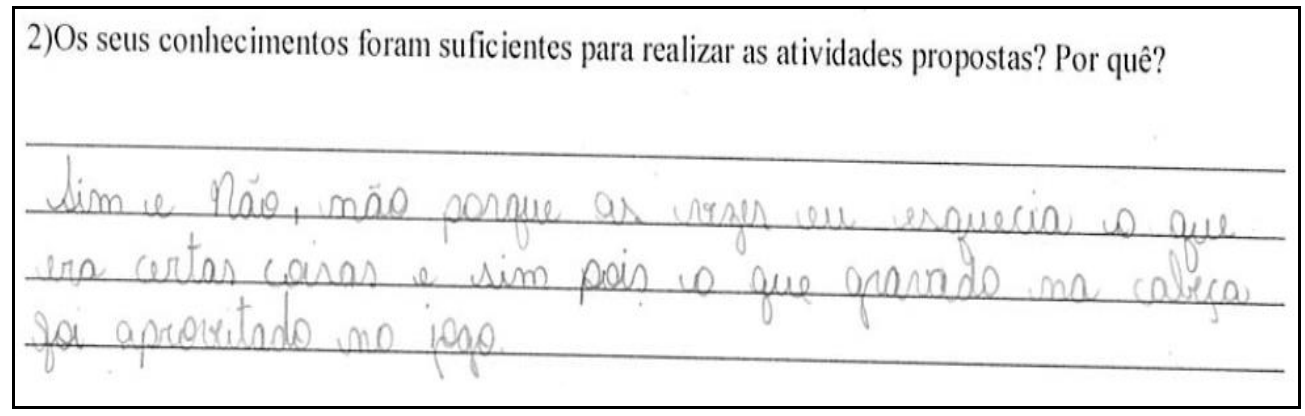

Figura 10 - Resposta do Aluno 20

Fonte: Imagem digitalizada pelas autoras. 
Uma das dificuldades em se trabalhar com jogos na sala de aula, segundo Strapason e Bisognin (2013), é o número de aulas necessárias para o desenvolvimento de atividades dessa natureza, o que, dependendo do conteúdo programático para o ano letivo, pode levar os professores a desistirem. Este fato foi observado em uma das respostas apresentadas à terceira pergunta do questionário.

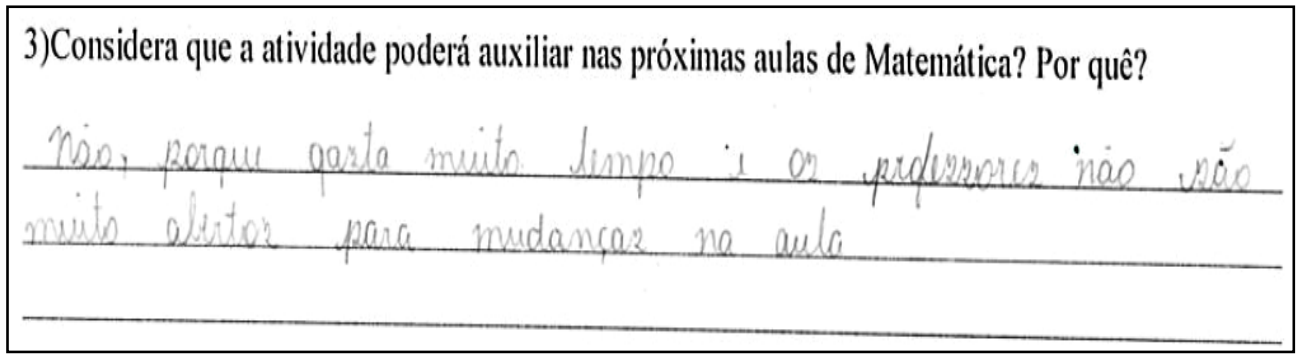

Figura 11- Resposta do Aluno 11

Fonte: Imagem digitalizada pelas autoras.

Embora o trabalho com jogos nas aulas de Matemática exija maior tempo de preparo e realização pelo professor, consideramos que recursos desse tipo, além de tornarem as aulas mais lúdicas, podem contribuir para a aprendizagem dos alunos em relação ao conteúdo de sólidos geométricos.

\section{CONSIDERAÇÕES FINAIS}

Consideramos que o Jogo dos Sólidos Geométricos teve, ainda que parcialmente, seus objetivos alcançados. Quanto à realização do jogo em si, julgamos que foi satisfatória. Embora os alunos tenham apresentado dificuldades em relação a alguns conteúdos, houve o envolvimento da turma com o jogo, ou seja, os alunos se sentirem motivados a jogar e a participar da aula. Além disso, os alunos souberam trabalhar, com excelência, em grupo, respeitando uns aos outros.

Já no cumprimento da segunda etapa da proposta, que consistia na resolução de algumas atividades, notamos a dificuldade dos alunos quanto à realização dos cálculos necessários. Isso nos causou certa estranheza pelo fato de termos sido informadas anteriormente pela professora que a turma era a melhor dentre os terceiros anos.

A experiência realizada com os alunos do $3^{\circ}$ ano do Ensino Médio nos levou a refletir 
sobre algumas potencialidades da utilização de jogos nas aulas de Matemática. Dentre elas, destacamos a possibilidade de revisar conteúdos de maneira atrativa e de diagnosticar as principais dificuldades dos alunos referentes ao conteúdo abordado. Nesse sentido, o jogo substituiu, por exemplos, uma lista de exercícios, uma avaliação diagnóstica ou uma aula de revisão. Outro potencial alcançado com o jogo foi a participação dos alunos durante a aula. Isso corrobora as ideias de Borin (2007) ao considerar que os jogos tornam as aulas de Matemática mais atrativas e interessantes, despertando o interesse dos alunos.

\title{
THE USE OF GAMES IN MATHEMATICS TEACHING: AN EXPERIENCE WITH MIDDLE SCHOOL STUDENTS
}

\begin{abstract}
The current work presents the report of an experiment on the use of the Game of Geometric Solids as a methodological resource for the teaching of Mathematics in Basic Education. The main purpose of the proposal was to establish concepts related to the theme - how to recognize geometric solids and their properties, and to calculate volume and total area - in a playful and attractive way. The game was applied to a class of the 3rd year of High School of a school of the state network of the city of Formiga (MG). The results showed that the use of games and challenging situations, such as didactic resources, allow a playful work of Mathematics in the classroom. In addition to having the purpose of getting students to learn the subject, games can also be seen as appropriate situations to work on other issues with students, such as socialization, cooperation, respect, among others.
\end{abstract}

Keywords: Experience report. Games. Mathematics.

\section{REFERÊNCIAS}

BORIN, J. Por que e para que utilizar jogos no ensino de Matemática. In: BORIN, J. Jogos e resolução de problemas: uma estratégia para as aulas de matemática. 6. ed. São Paulo: CAEM/ IME- USP, 2007. p. 8-18; 76-78.

BRASIL. Secretaria de Educação Fundamental. Parâmetros Curriculares Nacionais: matemática. Brasília, DF: MEC/SEF, 1998. Disponível em: <http//:portal.mec.gov.br/seb/ arquivos/pdf/matemática.pdf>. Acesso em: 12 jul. 2015.

GRANDO, R. C. O conhecimento matemático e o uso de jogo na sala de aula. 2000. 239 f. Tese (Doutorado em Educação Matemática) - Faculdade de Educação, Universidade Estadual de Campinas, Campinas, 2000. Disponível em: <www.bibliotecadigital.unicamp.br/document /list.php?tid=7>. Acesso em: 12 jul. 2015. 
MACEDO, L.; PETTY, A. L. S.; PASSOS, N. C. 4 Cores, senha e dominó. São Paulo: Casa do Psicólogo, 1997. 167 p.

NACARATO, A. M. Eu trabalho primeiro no concreto. Revista de Educação Matemática, n. 9, p. 1-6, 2005.

OFICINA: Jogo dos Poliedros. Disponível em: <http://porteiras.s.unipampa.edu.br/pibid/ files/2012/01/Mat-PDP-Oficina_Jogo_dos_Poliedros.pdf >. Acesso em: 21 maio 2015.

RÊGO, R. M; RÊGO, R. G. Desenvolvimento e uso de materiais didáticos no ensino de matemática. In: LORENZATO, S. (Org.). O laboratório de ensino de matemática na formação de professores. Campinas, SP: Autores associados, 2006. p. 39-56.

STRAPASON, L. P. R; BISOGNIN, E. Jogos pedagógicos para o ensino de funções no primeiro ano do ensino médio. Bolema, Rio Claro, SP, v. 27, n. 46, p. 579-595, ago. 2013.

\section{APÊNDICE A - Roteiro do Jogo dos Sólidos Geométricos}

Atividade 1: Nesta tabela a dupla deverá fazer o registro de todas as famílias que conseguiu identificar durante o jogo. Após o término do jogo a tabela será completada de acordo com as famílias encontradas pela dupla adversária para que as próximas atividades possam ser realizadas.

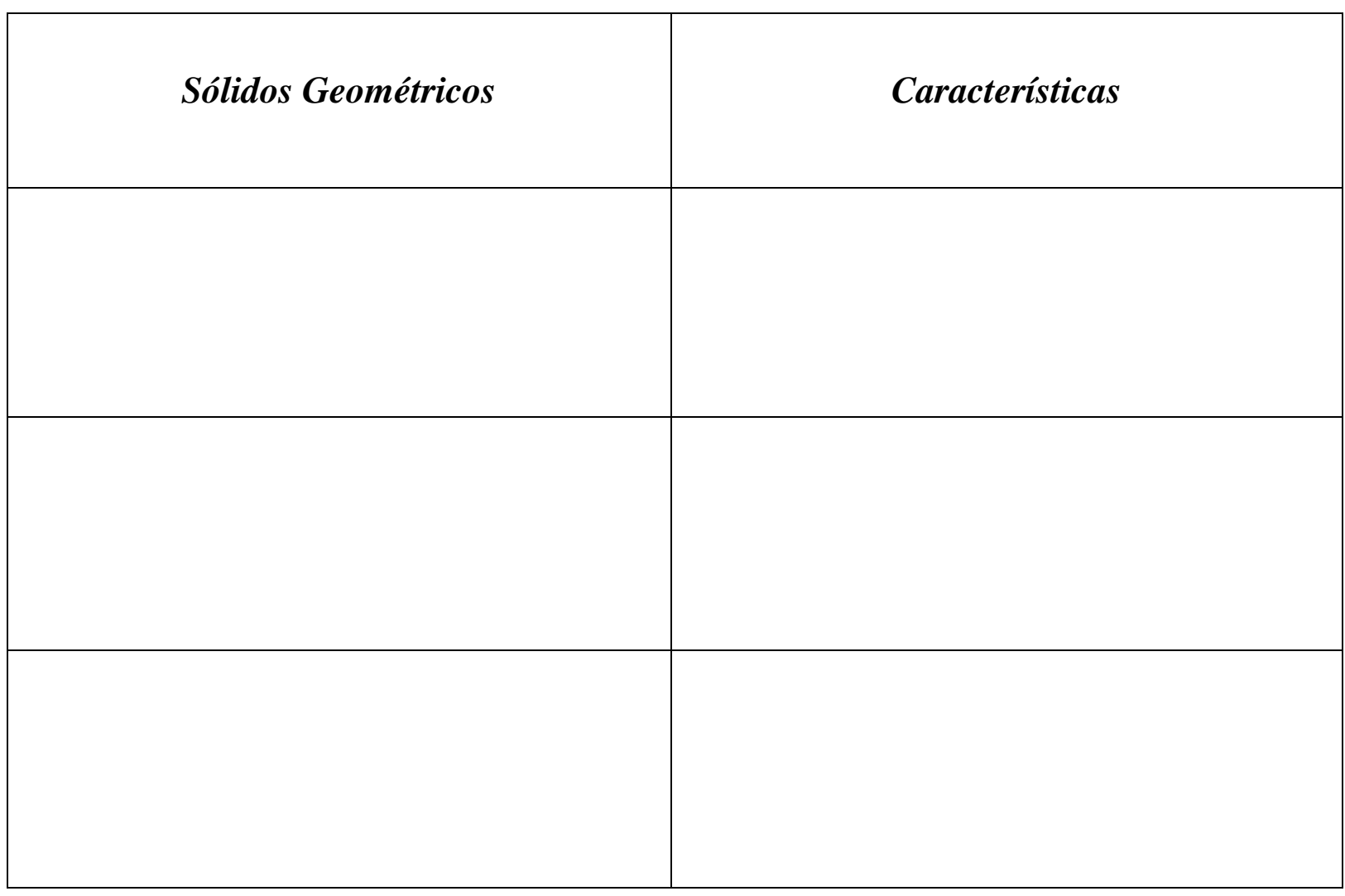


Atividade 2: Marque com Verdadeiro $(V)$ ou Falso $(F)$ as seguintes afirmações. Corrija as afirmações falsas:

a) O prisma de base pentagonal possui: 10 vértices; 7 faces e 15 arestas.

b) A fórmula para calcular o volume do cilindro é: $V=r^{2} \cdot h$.

c) Num paralelepípedo reto, as arestas da base medem $8 \mathrm{dm}$ e $6 \mathrm{dm}$, e a altura mede $4 \mathrm{dm}$.

Seu volume é $V=19,2 \mathrm{~m}^{3}$ e sua área total é $A_{T}=104 \mathrm{dm}^{2}$.

d) Um cubo de aresta $3 \mathrm{~cm}$ tem volume $V=9 \mathrm{~cm}^{3}$

Registre seus cálculos aqui:

Atividade 3: Vamos pensar! Você precisa embrulhar uma caixa com todas as medidas iguais a $10 \mathrm{~cm}$. Qual a quantidade de papel $\mathrm{em}^{\mathrm{cm}}{ }^{2}$ que você deverá usar? Como você chegou a essa resposta?

Registre seus cálculos aqui: 


\section{APÊNDICE B - Questionário para avaliação da atividade}

Sua opinião é muito importante para aprimorarmos nosso trabalho. Utilize este espaço para críticas, sugestões ou comentários sobre a atividade realizada na aula de hoje. Obrigada!

1) Qual a sua opinião quanto à aula/atividade de hoje?

2) Os seus conhecimentos foram suficientes para realizar as atividades propostas? Por quê?

3) Considera que a atividade poderá auxiliar nas próximas aulas de Matemática? Por que?

4) Destaque pontos positivos e negativos da atividade.

\section{DADOS DOS AUTORES}

\section{Suélen Costa Braz}

E-mail: suelemcostabe@hotmail.com

Currículo lattes: http://lattes.cnpq.br/3009394699054430

Mestranda em Educação em Ciências pela Universidade Federal de Itajubá e graduada em Licenciatura em Matemática pelo Instituto Federal de Minas Gerais - Campus Formiga. Atualmente está vinculada à Universidade Federal de Itajubá - Campus Itajubá.

\section{Thamara Kristina Miranda}

E-mail: thamarakm@hotmail.com

Currículo lattes: http://lattes.cnpq.br/0129795762474421 
Graduada em Licenciatura em Matemática pelo Instituto Federal de Minas Gerais - Campus Formiga. Atualmente é professora de Educação Básica da Escola Estadual Monsenhor Alfredo Dohr.

\section{Cirléia Pereira Barbosa}

E-mail: cirleia.barbosa@ifmg.edu.br

Currículo lattes: http://lattes.cnpq.br/3425389275119294

Doutoranda em Ensino de Ciências e Matemática pela Universidade Cruzeiro do Sul e mestra em Educação Matemática pela Universidade Federal de Ouro Preto (MG). Atualmente é professora do Ensino Básico, Técnico e Tecnológico do Instituto Federal de Minas Gerais Campus Formiga. 